Revista Brasileira de Agricultura Irrigada v.14, nº.1, p. 3835 - 3843, 2020

ISSN 1982-7679 (On-line)

Fortaleza, CE, INOVAGRI - http://www.inovagri.org.br

DOI: $10.7127 /$ rbai.v14n1001079

Protocolo 1079.20 - 08/04/2020 Aprovado em 30/03/2020

\title{
PRODUÇÃO DE ESPIGAS DE MILHO VERDE IRRIGADO SOB INFLUÊNCIA DO ESPAÇAMENTO E DA DENSIDADE DE PLANTAS
}

\author{
Rafael Ferro Silva ${ }^{1}$, Disraeli Reis da Rocha ${ }^{2}$, Poliana Rocha D’Almeida Mota ${ }^{3}$
}

\begin{abstract}
RESUMO
A pesquisa versou sobre o desempenho agronômico da cultivar AG 1051 para a produção de milho verde sob condições de irrigação, submetida a diferentes espaçamentos e densidades. $\mathrm{O}$ experimento foi conduzido no campo experimental do Colégio Técnico de Teresina (CTT), vinculado à Universidade Federal do Piauí, em Teresina, Piauí, Brasil. Utilizou-se o delineamento experimental em parcelas subdivididas com seis tratamentos principais (espaçamentos: 0,5;0,6;0,7;0,8 0,9 e 1,0 $\mathrm{m})$, quatro tratamentos secundários (densidades: 30.000, 40.000, 50.000 e 60.000 plantas ha $^{-1}$ ) e quatro repetições dispostas em blocos casualizados. Foram analisadas a massa das espigas e a produtividade de grãos leitosos. Verificou-se que os maiores rendimentos de espigas verdes comerciais e de grãos leitosos, foram obtidos nos espaçamentos entre fileiras reduzidos de 0,5 e 0,6 m. Os máximos rendimentos de espigas verdes comerciais, em todos os espaçamentos entre fileiras, foram obtidos em densidades compreendidas entre 47.319 e 48.754 plantas ha ${ }^{-1}$. As maiores produtividades de grãos leitosos foram obtidas em densidades situadas entre 46.739 e 49.887 plantas $\mathrm{ha}^{-1}$.
\end{abstract}

Palavras chave: Zea Mays L., população de plantas, arranjo de plantas, irrigação, AG 1051.

\section{PRODUCTION OF STEMS OF GREEN CORN IRRIGATED UNDER THE INFLUENCE OF SPACING AND PLANT DENSITY}

\footnotetext{
ABSTRACT

The research was about the agronomic performance of cultivar AG 1051 for the production of green corn under irrigation conditions, submitted to different spacings and densities. The experiment was

${ }^{1}$ Engenheiro Agrônomo pelo Centro de Ciências Agrárias, Universidade Federal do Piauí. Teresina, Piauí, Brasil. ferrosilva@gmail.com

${ }^{2}$ Engenheiro Agrônomo, Doutor. Departamento de Fitotecnia, Centro de Ciências Agrárias, Universidade Federal do Piauí, Campus Agrícola da Socopo, Socopo, 64049-550, Teresina, Piauí, Brasil. (86) 3215-5747. disraelireisdarocha@gmail.com

3 Engenheira Agrônoma, Doutora. Departamento de Engenharia Agrícola e Solos, Centro de Ciências Agrárias, Universidade Federal do Piauí, Campus Agrícola da Socopo, Socopo, 64049-550, Teresina, Piauí, Brasil. (86) 32155745.poliana@ufpi.edu.br
} 
conducted in the experimental field of the Technical College of Teresina (CTT), belonging to the Federal University of Piauí, Teresina, Piauí, Brazil. The experimental design was in split plots with six main treatments (spacings: 0.5, 0.6, 0.7, 0.80 .9 and $1.0 \mathrm{~m}$ ), four secondary treatments (densities: $30,000,40,000,50,000$ and 60,000 plants $\mathrm{ha}^{-1}$ ) and four replications arranged in randomized blocks. Ear weight and milky grain yield were analyzed. It was found that the highest yields of commercial green ears and milky grains were obtained in reduced row spacings of 0.5 and $0.6 \mathrm{~m}$. Maximum yields of commercial green spike in all row spacings were obtained at densities ranging from 47,319 to 48,754 plants $\mathrm{ha}^{-1}$. The highest yields of milky grains were obtained at densities between 46,739 and 49,887 plants ha ${ }^{-1}$.

Keywords: Zea Mays L., plant population, plant arrangement, irrigation, AG 1051.

\section{INTRODUÇÃO}

O cultivo do milho para colheita de espigas verdes é uma atividade alternativa para pequenos produtores devido ao maior valor de comercialização quando comparado ao milho para produção de grãos. Com alto valor nutritivo, o milho verde pode ser utilizado para consumo in natura de espigas cozidas ou processadas, apresentando consumo constante durante o ano (SANTOS et al., 2015).

No Piauí, de acordo com Rocha et al. (2011) a maior produção e consumo de milho verde ocorrem na Grande Teresina, região formada por treze municípios piauienses, mais a vizinha cidade maranhense de Timon, com uma população superior a 1,2 milhão de habitantes.

Nessa região, na estação chuvosa (janeiro/maio), o milho é cultivado em condições de sequeiro, com o uso principalmente de variedades e híbridos duplos não indicados especificamente para produção de milho verde; no período de junho/dezembro, são utilizados cultivos irrigados por aspersão convencional, com uso predominante de híbridos duplos com versatilidade de uso (ROCHA et al., 2011).

De acordo com Cruz et al. (2007) a densidade de plantio ideal é função da cultivar, da disponibilidade de água e de nutrientes, e normalmente, cultivares mais precoces, de menor porte e mais eretas, permitem o uso de densidades mais elevadas e espaçamento menor $(0,5 \mathrm{~m})$.

De acordo com Serpa et al. (2012), a utilização de altas densidades é uma estratégia eficiente para otimizar a produtividade de grãos do milho.

Cardoso et al. (2010) observaram que o número de espigas verdes por planta aumenta com a redução do espaçamento e os maiores pesos de espigas verdes são obtidos nas maiores densidades e menores espaçamentos. As maiores produtividades de espigas verdes foram obtidas com a combinação do menor espaçamento entre fileiras $(0,6 \mathrm{~m})$ e com a maior densidade de plantas $\left(6,25\right.$ plantas $\left.\mathrm{m}^{-2}\right)$.

Mantovani et al. (2015), ao avaliarem o cultivo de milho concluíram que a redução para o espaçamento de $0,45 \mathrm{~m}$ entre fileiras resultou em melhor rendimento, e que essa é uma tendência nas regiões produtoras brasileiras, assegurado pelo potencial genético das cultivares lançadas e pela necessidade de aumento da produtividade. Rocha et al. (2011) concluíram que o incremento no número de plantas da cultivar de milho AG 1051 possibilitou alongamento na altura da planta e elevou o ponto de inserção da primeira espiga, com redução no comprimento e diâmetro das espigas. Justificam pela maior competição por água, luz e nutrientes. As melhores características de comprimento, peso e número de espigas comerciais, foram obtidas na população de 50.000 plantas ha $^{-1}$.

Diante do exposto, o objetivo deste trabalho foi avaliar o efeito da população de plantas e do espaçamento entre fileiras nas características agronômicas de peso da espiga comercial e produtividade de grãos leitosos da variedade de milho verde AG 1051, sob condições de irrigação, no município de Teresina, Estado do Piauí, Brasil. 


\section{PRODUÇÃO DE ESPIGAS DE MILHO VERDE IRRIGADO SOB INFLUÊNCIA DO ESPAÇAMENTO E DA DENSIDADE DE PLANTAS}

\section{MATERIAL E MÉTODOS}

O experimento foi conduzido na área experimental do Colégio Técnico de Teresina (CTT), da Universidade Federal do Piauí, localizado no município de Teresina, Estado do Piauí, Brasil, sob as coordenadas com 5'5'12" de Latitude S, 4248'42” de Longitude W e altitude de $72 \mathrm{~m}$.

O solo da área experimental foi classificado pelo Laboratório de Solos (LASO) do Centro de Ciências Agrárias da Universidade Federal do Piauí como Argissolo Vermelho-Amarelo eutrófico (SANTOS et al., 2018), com textura arenosa e relevo suave ondulado.

Utilizou-se o delineamento experimental em parcelas subdivididas: na parcela, seis tratamentos principais (espaçamentos entre fileiras); e na subparcela, quatro tratamentos secundários (densidade de plantas), com quatro repetições, dispostas em blocos casualizados. Cada subparcela foi constituída por quatro fileiras com cinco metros de comprimento, distando de acordo com os espaçamentos testados, considerando-se como área útil as duas parcelas centrais.

Os espaçamentos entre fileiras avaliados foram: 0,$5 ; 0,6 ; 0,7 ; 0,8 ; 0,9$ e $1,0 \mathrm{~m}$. As densidades estudadas foram: 30.000; 40.000; 50.000 e 60.000 plantas ha $^{-1}$.

A área utilizada para a condução do experimento foi previamente submetida a aração e gradagem. A calagem foi realizada sete meses antes do plantio, e apresentava ainda saturação por base igual a $65 \%$, compatível com a cultura do milho, conforme análise de fertilidade do solo efetuada pelo LASO/UFPI.

A adubação de semeadura, efetuada por meio do formulado NPK 05-30-15, na dose de $400 \mathrm{~kg} \mathrm{ha}^{-1}$, foi realizada manualmente, no sulco com $0,15 \mathrm{~m}$ de profundidade. A adubação de cobertura foi realizada manualmente, a 0,20 m das fileiras das plantas e incorporadas a $0,05 \mathrm{~m}$ de profundidade. $\mathrm{O}$ adubo nitrogenado (uréia) foi parcelado em duas doses iguais de $60 \mathrm{~kg} \mathrm{ha}^{-1}$ de $\mathrm{N}$, aplicando-se a primeira dose quando a planta contava com 3 a 4 folhas. A segunda aplicação foi realizada no estágio de 8 a 10 folhas completamente desenvolvidas. A adubação potássica de cobertura foi realizada de uma única vez, na dose de $60 \mathrm{~kg} \mathrm{ha}^{-1}$ de $\mathrm{K}_{2} \mathrm{O}$, utilizando cloreto de potássio, juntamente com a uréia na primeira adubação de cobertura, de acordo com Rocha et al. (2011).

A semeadura de milho (cultivar AG 1051) foi efetuada no dia 10 de outubro de 2016, manualmente, colocando-se duas sementes por cova, a distâncias correspondentes às densidades estabelecidas. $\mathrm{O}$ desbaste foi realizado quando as plantas apresentavam duas a três folhas totalmente expandidas, deixando-se uma planta por cova.

Para irrigação utilizou-se um sistema por aspersão convencional, com turno de rega diário, aplicando lâminas de água crescentes, de acordo com a evolução do crescimento e desenvolvimento das plantas, atingindo lâmina d'água da ordem de $8,5 \mathrm{~mm} \mathrm{dia}^{-1}$, nos estágios V18 e R3 (último estádio vegetativo, e de grão leitoso, respectivamente). A lâmina de água aplicada foi calculada em função da evapotranspiração de referência para a cultura do milho e pela condição de armazenamento do solo a partir das características físicas reveladas pela análise do solo realizada pelo LASO (7\% de capacidade de campo, 3,5\% de ponto de murcha permanente e $1,5 \mathrm{~kg} \mathrm{dm}^{-3} \mathrm{de}$ solo).

As plantas infestantes foram manejadas por meio de capinas, utilizando enxadas, aos 10, 20 e 30 dias após a emergência. Foram realizadas três pulverizações para o controle da lagarta do cartucho (Spodoptera frugiperda), aos 10, 20 e 30 dias após a emergência, utilizando-se o inseticida piretroide Deltametrina, na dose recomendada pelo fabricante.

As colheitas foram realizadas manualmente, no período compreendido entre 16 e 20 de dezembro de 2016, aos 67 e 71 dias após a semeadura, à medida que as espigas foram atingindo o ponto de milho verde, ou seja, quando os grãos se apresentavam com teor de 70 a $80 \%$ de umidade, entre os estágios leitoso (R3) e pastoso (R4). 
Foram consideradas espigas verdes comerciais empalhadas, aquelas com comprimento superior a $23 \mathrm{~cm}$, bem granadas, isentas de pragas e doenças (PAIVA JÚNIOR et al., 2001), com peso mínimo de 250 gramas.

Foram avaliadas a massa de espigas comerciais empalhadas (determinado pela massa em balança de todas as espigas comerciais empalhadas, em $\mathrm{kg} \mathrm{ha} \mathrm{ha}^{-1}$ e a produtividade de grãos leitosos de espigas comerciais (determinada pela massa de grãos de todas as espigas comercias da parcela, cortadas rente ao sabugo, em kg ha-1).

Os resultados foram submetidos a uma análise de variância pelo teste $\mathrm{F}(P<0,01)$, de acordo com o delineamento experimental adotado. Observado efeito significativo, as médias foram comparadas pelo teste de Tukey a 5\% de significância. Para estudar o efeito da densidade de plantas sobre as características avaliadas, os dados foram submetidos à análise de regressão polinomial até o $2^{\circ}$ grau, utilizando o software ASSISTAT, assistência estatística versão 7.7 (SILVA; AZEVEDO, 2016).

\section{RESULTADOS E DISCUSSÃO}

O resultado da análise de variância revelou que a massa das espigas empalhadas foi influenciada pela densidade de plantas, pelo espaçamento entre fileiras e pela interação entre os dois fatores (Tabela 1).

Tabela 1. Análise de variância da massa de espigas de milho verde comerciais empalhadas, em função de quatro densidades de plantas (D) e seis espaçamentos entre fileiras (E).

\begin{tabular}{cc}
\hline Fontes de variação & Massa de espigas empalhadas $\left(\mathrm{kg} \mathrm{ha}^{-1}\right)$ \\
\hline Densidade de plantas (plantas ha $\left.{ }^{-1}\right)-\mathrm{D}$ & $540,31^{*}$ \\
\hline Teste F & $348,03 *$ \\
\hline Espaçamento entre fileiras (m) - E & 0,27395 \\
\hline Teste F & $4,2043^{*}$ \\
\hline DMS (Tukey) a 5 \% & 2,39 \\
\hline Teste F (D x E) & 2,61 \\
\hline CV (\%) densidade de plantas & \\
\hline CV (\%) espaçamento entre fileiras & \\
\hline
\end{tabular}

* Significativo ao nível de $1 \%$.

Para a variável massa de espigas comerciais empalhadas os resultados mostraram que os espaçamentos 0,5 e $0,6 \mathrm{~m}$ entre fileiras de plantas de milho, comportaram-se estatisticamente iguais entre si e superiores aos demais tratamentos $(0,7$; $0,8 ; 0,9$ e $1,0 \mathrm{~m})$. A partir de $0,6 \mathrm{~m}$, a massa de espigas foi decrescente com o aumento do espaçamento entre fileiras de plantas.

Estes resultados estão de acordo com Mantovani et al. (2015) e Cardoso et al. (2010). Santos et al. (2015), em pesquisa realizada também com AG 1051, encontraram um total de $14.293 \mathrm{~kg} \mathrm{ha}^{-1}$, mas tendo sido adotados critérios diferentes para considerar espigas comerciais.

De acordo com Cruz et al. (2007), as vantagens do uso de menores espaçamentos entre fileiras para obter maior rendimento de espigas verdes de milho estão relacionadas com a rápida cobertura do solo, favorecendo maior supressão das plantas indesejáveis, com consequente redução de reinfestação e menor evaporação. Ainda, a distribuição equidistante de plantas na área, aumentando a eficiência de utilização de luz solar, de água e de nutrientes.

Os resultados de produtividade de espigas em função do espaçamento e do arranjo de plantas obtidos neste experimento estão, também, concordantes com Cruz et al. (2007). Entre os espaçamentos testados, 0,5 m entre fileiras, o mais produtivo, juntamente com $0,6 \mathrm{~m}$, é o de maior equidistância entre plantas (Figura 1).

Especificamente para o milho, sob densidade excessiva de plantas, condição em 


\section{PRODUÇÃO DE ESPIGAS DE MILHO VERDE IRRIGADO SOB INFLUÊNCIA DO ESPAÇAMENTO E DA DENSIDADE DE PLANTAS}

que a perda de produção individual é superior ao ganho com aumento de plantas por área, pode ocorrer também, influência de outros fatores como a defasagem entre os florescimentos masculino (pendoamento) e feminino (espigamento).

Segundo Rodrigues et al. (2009), isso resulta em menor polinização, reduzindo consequentemente, o número de grãos por espiga.

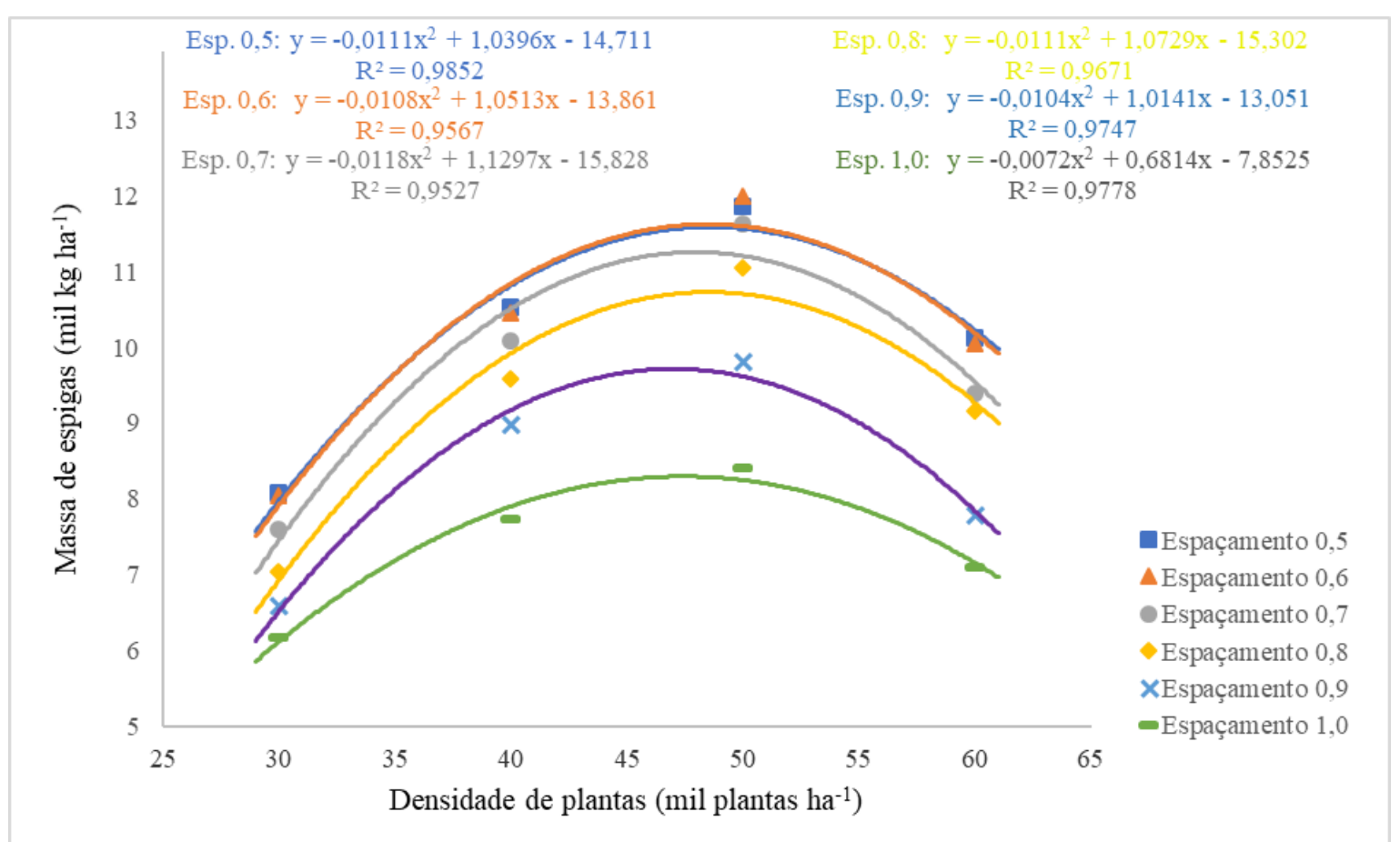

Figura 1. Massa de espigas de milho verde comerciais empalhadas por ha ${ }^{-1}$, em função de quatro densidades de plantas $(30.000,40.000,50.000$ e 60.000 plantas $)$ e seis espaçamentos entre fileiras $(0,5 ; 0,6 ; 0,7 ; 0,8 ; 0,9$ e 1,0 $\mathrm{m})$.

Por meio da regressão polinomial (Figura 1) constatou-se que as massas de espigas comerciais empalhadas, nos espaçamentos 0,$5 ; 0,6 ; 0,7 ; 0,8 ; 0,9$ e $1,0 \mathrm{~m}$ entre fileiras de plantas de milho, responderam de acordo com uma equação quadrática, tendo sido a máxima massa de espigas comerciais empalhadas obtidas nas densidades de 48.754 , $48.671,47.868,48.238,48.750$ e 47.319 plantas ha ${ }^{-1}$, respectivamente.

Estes resultados estão de acordo com os observados por Pereira Filho (2003), Fornasieri Filho (2007) e Rocha et al. (2011). Pereira (2003) e Fornasieri Filho (2007) relataram que o rendimento de uma lavoura de milho eleva-se com o aumento da população de planta até atingir uma densidade ótima, a partir da qual ocorre decréscimo progressivo de produtividade, em razão da competição por água, luz e nutrientes.

Em trabalho desenvolvido também na região de Teresina, Piauí, Nascimento et al. (2015), obtiveram produtividade média de espigas verdes empalhadas, AG 1051, de $13.453,13 \mathrm{~kg} \mathrm{ha}^{-1}$ com estande de 50.000 plantas ha- ${ }^{-1}$.

Gundim et al. (2019) ao avaliarem espaçamentos que resultaram em densidades de 10.000 a 80.000 plantas ha ${ }^{-1}$, obtiveram nos maiores estandes as máximas produtividades de espigas verdes, tendo sido cultivado o AG 1051. Segundo Silva et al. (2015), em estudo avaliando seis cultivares para produção de milho verde em Roraima, dentre elas o AG 1051 , obtiveram produtividade de $5.406,25 \mathrm{~kg}$ $\mathrm{ha}^{-1}$ de espigas despalhadas, para uma densidade populacional de 45.000 plantas $\mathrm{ha}^{-1}$, 
em condições não irrigadas. Silva et al. (2018), em pesquisa desenvolvida com milho verde no semiárido, observaram acréscimo na massa de espigas verdes despalhadas, com produtividade máxima alcançada de $4.590 \mathrm{~kg}$ $\mathrm{ha}^{-1}$, na densidade de plantio de 67.000 plantas $\mathrm{ha}^{-1}$, ao avaliarem tensões de água no solo. Em estudo realizado avaliando cinco espaçamentos entre as plantas na semeadura do milho verde AG 1051, que resultaram na população de 50.000, 55.555, 62.500, 71.429 e
83.333 plantas ha ${ }^{-1}$, Soares Neto et al. (2017) concluíram que o estande de 71.429 plantas $\mathrm{ha}^{-1}$ apresentou-se mais indicado para o cultivo de milho verde irrigado nas condições edafoclimáticas da cidade de Arapiraca, Estado de Alagoas.

O resultado da análise de variância, mostrou a influência da densidade de plantas, do espaçamento entre fileiras e da interação entre os dois fatores, no rendimento de grãos leitosos de milho verde (Tabela 2).

Tabela 2. Análise de variância de rendimentos de grãos leitosos de milho verde, obtidos com quatro densidades de plantas (D) e seis espaçamentos entre fileiras (E).

\begin{tabular}{cc}
\hline Fontes de variação & \multirow{2}{*}{ Rendimento de grãos leitosos $\left(\mathrm{kg} \mathrm{ha}^{-1}\right)$} \\
\hline Densidade de plantas (plantas ha $\left.{ }^{-1}\right)-\mathrm{D}$ & $261,33^{*}$ \\
\hline Teste F & $348,03 *$ \\
\hline Espaçamento entre fileiras (m) - E & 0,27395 \\
\hline Teste F & $2,6299 *$ \\
DMS (Tukey) a 5 \% & 4,11 \\
\hline Teste F (D x E) & 3,53 \\
\hline CV\% densidade de plantas &
\end{tabular}

* Significativo ao nível de $1 \%$.

O melhor desempenho foi obtido no espaçamento $0,5 \mathrm{~m}$ entre fileiras. Observou-se também, que o rendimento de grãos leitosos foi crescente do menor para o maior espaçamento entre fileiras de plantas de milho. Estes resultados estão de acordo com Andrade et al. (2002) e Amaral Filho et al. (2005), e reforçam a tese defendida por Cruz et al. (2007), para quem o principal motivador da produção de grãos de espigas de milho verde é a distribuição equidistante de plantas na área, com consequente otimização do uso da luz solar, da água e dos nutrientes. Silva et al. (2014), ao estudarem o efeito de diferentes espaçamentos entrelinhas em híbridos de milho, encontraram que o de $0,45 \mathrm{~m}$ promoveu aumento na produtividade da cultura.

Os espaçamentos entre fileiras 0,$5 ; 0,6$; 0,$7 ; 0,8 ; 0,9$ e $1,0 \mathrm{~m}$, comportaram-se de acordo com uma equação quadrática, obtendose o máximo rendimento na massa de grãos leitosos nas densidades de 48.930, 47.763, 49.887, 47.725, 46.739 e 48.456 plantas ha ${ }^{-1}$, respectivamente (Figura 2). 


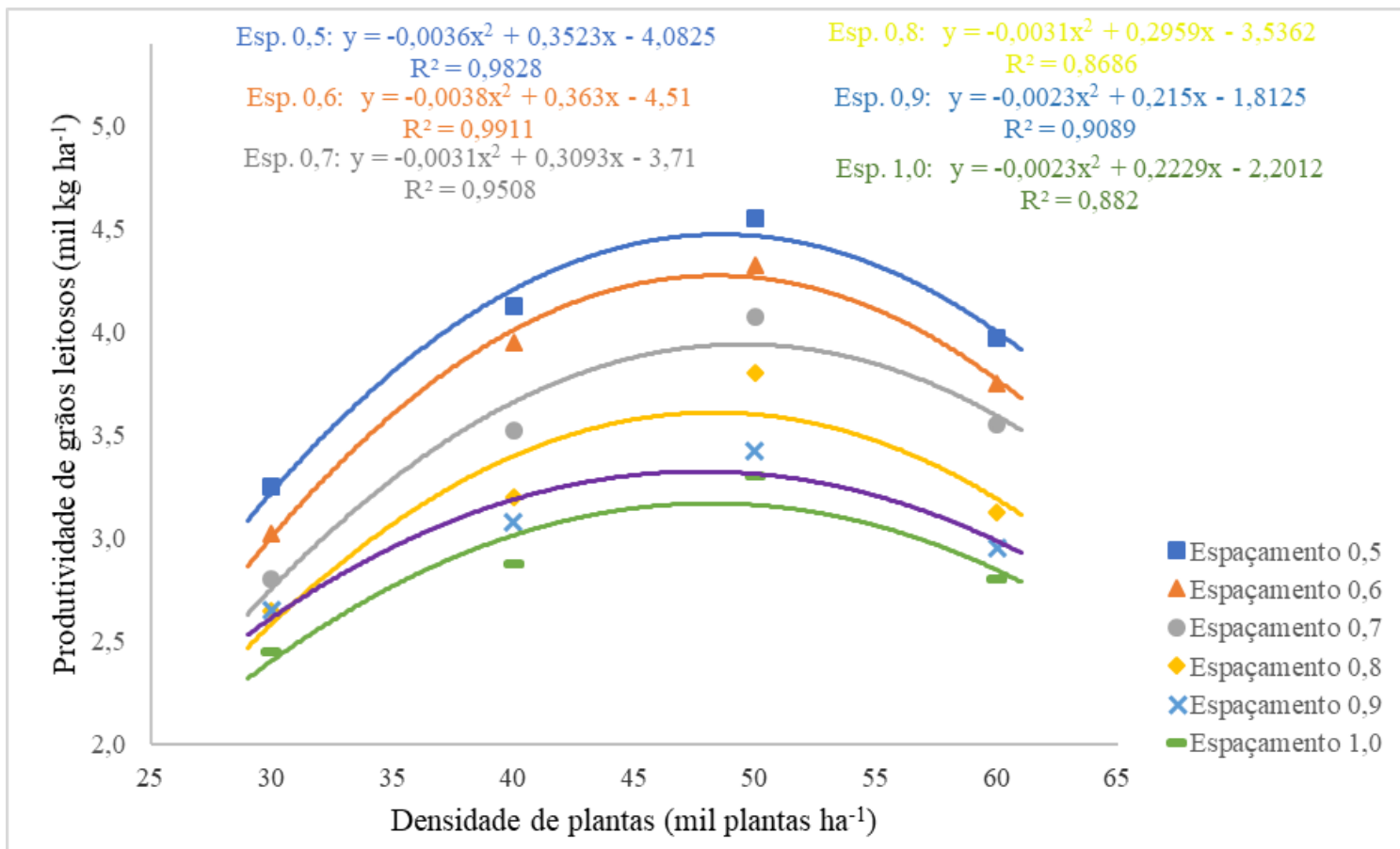

Figura 2. Produtividade de grãos leitosos $\left(\mathrm{kg} \mathrm{ha}^{-1}\right)$, em função de quatro densidades de plantas $(30.000,40.000$, 50.000 e 60.000 plantas) e seis espaçamentos entre fileiras $(0,5 ; 0,6 ; 0,7 ; 0,8 ; 0,9$ e $1,0 \mathrm{~m})$.

Com relação ao efeito da densidade de plantas na variável avaliada, observou-se o crescimento na produtividade de grãos leitosos até a densidade de 50.000 plantas ha ${ }^{-1}$, estando assim de acordo com Pereira Filho (2003) e Fornasieri Filho (2007).

Trabalhando com plantas decumbentes, tipo AG 1051, utilizada neste experimento, Strieder et al. (2007) e Rocha et al. (2011) observaram, também, comportamento semelhante para produção de grãos leitosos com o aumento da população de plantas. Cox (1996), já havia relatado a influência da população de plantas na massa de grãos leitosos de milho.

Considerando apenas o melhor resultado, proporcionado pelo espaçamento 0,5 $\mathrm{m}$, com produtividades máximas de 11.728 $\mathrm{kg}$ de espigas comerciais empalhadas $\mathrm{ha}^{-1} \mathrm{e}$ de $4.932 \mathrm{~kg}$ de grãos leitosos ha ${ }^{-1}$, entende-se que a porcentagem de grãos leitosos foi de $42,05 \%$ com relação a massa de espigas. Rocha et al. (2011), trabalhando com a mesma cultivar e no mesmo ecossistema, obtiveram máxima relação grãos leitosos/espigas verdes na ordem de $36,4 \%$.
Os dados obtidos no experimento, para a produtividade de grãos leitosos, reforçam a tese defendida por Sangoi (2001), para quem baixa densidade de plantas aumenta a interceptação de luz solar por área, favorecendo a síntese de fotoassimilados e consequentemente a produção de grãos por planta, mas reduzindo a produtividade por área.

\section{CONCLUSÕES}

Maiores rendimentos de espigas verdes comerciais e de grãos leitosos são obtidos em espaçamentos reduzidos com 0,5 e $0,6 \mathrm{~m}$.

Os máximos rendimentos de espigas verdes comerciais, em todos os espaçamentos entre fileiras, são obtidos em densidades compreendidas entre 47.319 e 48.754 plantas $\mathrm{ha}^{-1}$.

As maiores produtividades de grãos leitosos são obtidas com densidades entre 46.739 e 49.887 plantas ha- 1 . 


\section{REFERÊNCIAS BIBLIOGRÁFICAS}

AMARAL FILHO, J. R.; FORNASIERI FILHO, D., FARINELLI, R. B, BARBOSA, J. C. Espaçamento, densidade populacional e adubação nitrogenada na cultura do milho. Revista Brasileira de Ciência do Solo, v. 29, n. 3, p. 467-473, 2005. http://dx.doi.org/10.1590/S010006832005000300017

ANDRADE, F. H.; CALVINO, P.; CIRILO, A.; BARBIERI, P. Yield responses to narrow rows depend on increased radiation interception. Agronomy Journal, v. 94, n. 5, p. 975980, 2002. 10.2134/agronj2002.9750

CARDOSO, M. J.; SILVA, A. R. da; ROCHA, L. M. P.; GUIMARÃES, P. E. de O.; SETUBAL, J. W. Rendimento de espigas verde de milho em relação ao espaçamento entre fileiras e a densidade de plantas. Horticultura Brasileira, v. 28, n. 2 (edição especial), p. S1432-S1435, 2010.

COX, W. J. Whole-plant physiological and yield responses of maize density. Agronomy Journal, v. 88, n. 3, p. 489496, 1996. 10.2134/agronj1996.00021962008800030 $022 \mathrm{x}$

CRUZ, J. C.; PEREIRA, F. T. F.; PEREIRA FILHO, I. A.; OLIVEIRA, A. C. de; MAGALHAES, P. C. Resposta de cultivares de milho à variação em espaçamento e densidade. Revista Brasileira de Milho e Sorgo, v. 6, n. 1, p. 60-73, 2007. http://dx.doi.org/10.18512/1980-

6477/rbms.v6n01p\%25p

FORNASIERI FILHO, D. Manual da cultura do milho. Jaboticabal: FUNEP, 2007, 576 p.

GUNDIM, A. da S.; CONCEIÇÃO, A. M. P. da; NOGUEIRA, J. C. A.; ROCHA, C.; SOUZA, L. P. de. Produtividade do milho verde irrigado por gotejamento na Amazônia Ocidental. Enciclopédia Biosfera, v. 16, n. 29, p. 1268-1279. 2019. http://dx.doi.org/10.18677/EnciBio_2019A 110

MANTOVANI, E. C.; CRUZ, J. C.; OLIVEIRA, A. C. de. Avaliação em campo de uma semeadora-adubadora para plantio de milho de alta densidade. Revista Brasileira de Milho e Sorgo, v. 14, n. 1, p. 38-48, 2015. http://dx.doi.org/10.18512/19806477/rbms.v14n1p38-48

PAIVA JÚNIOR, M. C.; PINHO, R. G. VON; PINHO, E. V. R. VON; RESENDE, S. G. Desempenho de cultivares para a produção de milho verde em diferentes épocas e densidades de semeadura em Lavras-MG. Ciência e Agrotecnologia, v. 25, n. 5, p.1235-1247. 2001.

PEREIRA FILHO, I. A. O cultivo do milho-verde. Brasília, Embrapa, 2003. $204 \mathrm{p}$.

ROCHA, D. R. da; FORNASIER FILHO, D.; BARBOSA, J. C. Efeitos da densidade de plantas no rendimento comercial de espigas verdes de cultivares de milho. Horticultura Brasileira, v. 29, n. 3, p. 392-397. 2011.

http://dx.doi.org/10.1590/S010205362011000300023

RODRIGUES, L. R.; GUADAGNIN, J. P.; PORTO, M. P. Indicações técnicas para o cultivo de milho e de sorgo no Rio Grande do Sul: safras 2009/2010 e 2010/2011. Veranópolis: FEPAGROSerra, 2009. 179 p.

SANGOI, L. Understanding plant density effects on maize growth and development; an important issue to maximize grain yield. Ciência Rural, v. 31, n. 1, p. 159168 , 2001. http://dx.doi.org/10.1590/S010384782001000100027 


\section{PRODUÇÃO DE ESPIGAS DE MILHO VERDE IRRIGADO SOB INFLUÊNCIA DO ESPAÇAMENTO E DA DENSIDADE DE PLANTAS}

SANTOS, H. G. dos; JACOMINE, P. K. T.; ANJOS, L. H. C. dos; OLIVEIRA, V. Á. de; LUMBRERAS, J. F.; COELHO, M. R.; ALMEIDA, J. A. de; ARAÚJO FILHO, J. C. de; OLIVEIRA, J. B. de; CUNHA, T. J. F. Sistema Brasileiro de Classificação de Solos. 5. ed. Brasília, DF: Embrapa, 2018.

SANTOS, N. C. B. dos; CARMO, S. A. do; MATEUS, G. P.; KOMURO, L. K.; PEREIRA, L. B.; SOUZA, L. C. D. de. Características agronômicas e de desempenho produtivo de cultivares de milho-verde em sistema orgânico e convencional. Semina: Ciências Agrárias, v. 36, n. 3 (Suplemento 1), p. 1807-1822, 2015. http://dx.doi.org/10.5433/1679-

0359.2015v36n3Sup11p1807

SERPA, M. da S.; SILVA, P. R. F. da; SANGOI, L.; VIEIRA, V. M.; MARCHESI, D. R. Densidade de plantas em híbridos de milho semeados no final do inverno em ambientes irrigados e de sequeiro. Pesquisa Agropecuária Brasileira, v. 47, n. 4, p. 541-549, 2012. http://dx.doi.org/10.1590/S0100204X2012000400010

SILVA, A. F.; SCHONINGER, L. S.; CAIONE, G.; KUFFEL, C.; CARVALHO, M. A. C. Produtividade de híbridos de milho em função do espaçamento e da população de plantas em sistema de plantio convencional. Revista Brasileira de Milho e Sorgo, v. 13, n. 2, p. 162-173, 2014. http://dx.doi.org/10.18512/19806477/rbms.v13n2p162-173

SILVA, F. A. S.; AZEVEDO, C. A. V. The Assistat Software Version 7.7 and its use in the analysis of experimental data. African Journal of Agricultural Research, v. 11, n. 39, p. 3733-3740, 2016.

https://doi.org/10.5897/AJAR2016.11522
SILVA， F. G. da; ASPIAZÚ, I.; OLIVEIRA, R. M. de; SILVA, K. M. de JESUS; SANTOS, S. R. dos; PORTUGAL, A. F.; MOREIRA, J. A. A.; BRITO, O. G.; SILVA, N. P. da. Tensão de água no solo para o reinício da irrigação de milho verde no semiárido. Revista Brasileira de Milho e Sorgo, v. 17, n. 2, p. 190-200, 2018 https://doi.org/10.18512/19806477/rbms.v17n2p190-200.

SILVA, G. C.; SCHMITZ, R.; SILVA, L. C. da; CARPANINI, G. G.; MAGALHÃES, R. C. Desempenho de cultivares para a produção de milho verde na agricultura familiar no sul de Roraima. Revista Brasileira de Milho e Sorgo, v. 14, n. 2, p. 273-282, 2015. https://doi.org/10.18512/1980-

6477/rbms.v14n2p273-282.

SOARES NETO, J.; SANTOS NETO, A. L. dos; SANTOS, W. M. dos; BARROS, D. T. S.; SOUZA, A. A. de; ALBUQUERQUE NETO, J. C. de. Performance of irrigated green corn cultivars in different plant populations at sowing. Revista Brasileira de Engenharia Agrícola e Ambiental, v. 21, n. 4, p. 267-272. 2017. https://doi.org/10.1590/1807-

1929/agriambi.v21n4p267-272

STRIEDER, M. L.; SILVA, P. R. F.; ARGENTA, G.; RAMBO, L.; SANGOI. L.; SILVA, A.; ENDRIGO, P. C. A resposta do milho irrigado ao espaçamento entrelinhas depende do híbrido e da densidade de plantas. Ciência Rural, v. 37, n. 3, p. 634-642, 2007. http://dx.doi.org/10.1590/S010384782007000300006 